NB This manuscript has been accepted for publication in Science. This version has not undergone final editing. Please refer to the complete version of record at http://www.sciencemag.org/. The manuscript may not be reproduced or used in any manner that does not fall within the fair use provisions of the Copyright Act without the prior, written permission of AAAS.

\title{
Building mountain biodiversity: geological and evolutionary processes
}

Authors: Carsten Rahbek ${ }^{1,2 *} \uparrow$, Michael K. Borregaard ${ }^{1} \dagger$, Alexandre Antonelli ${ }^{3,4}$, Robert K. Colwell ${ }^{1,5,6}$, Ben G. Holt ${ }^{1}$, David Nogués-Bravo ${ }^{1}$, Christian M. Ø. Rasmussen ${ }^{1,7}$, Katherine Richardson ${ }^{1}$, Minik T. Rosing ${ }^{8}$, Robert J. Whittaker ${ }^{1,9}$, Jon Fjeldså ${ }^{1}$.

\section{Affiliations:}

${ }^{1}$ Center for Macroecology, Evolution and Climate, GLOBE Institute, University of Copenhagen, 15 Denmark.

${ }^{2}$ Department of Life Sciences, Imperial College London, Ascot SL5 7PY, UK.

${ }^{3}$ Royal Botanic Gardens, Kew, Surrey, TW9 3AE, UK

${ }^{4}$ Gothenburg Global Biodiversity Centre, SE-41319, Göteborg, Sweden

${ }^{5}$ Department of Ecology and Evolutionary Biology, University of Connecticut, Storrs,

20 CT 06269, USA.

${ }^{6}$ University of Colorado Museum of Natural History, Boulder, CO 80309, USA.

${ }^{7}$ Natural History Museum of Denmark, University of Copenhagen, Denmark.

${ }^{8}$ Section for GeoBiology, GLOBE Institute, University of Copenhagen, Denmark.

${ }^{8}$ School of Geography \& the Environment, University of Oxford, South Parks Rd, OX1 3QY, 25 UK.

*Correspondence to: crahbek@ @nm.ku.dk.

$\dagger$ These authors contributed equally.

Abstract: Mountain regions are unusually biodiverse, with especially rich aggregations of smallranged species that form centers of endemism. Mountains play an array of important roles for Earth's biodiversity, and impact neighboring lowlands through biotic interchange, changes in regional climate, and nutrient run-off. The high biodiversity of certain mountains reflects the interplay of multiple evolutionary mechanisms: enhanced speciation rates with unique opportunities for co-existence and persistence of lineages, shaped by long-term climatic changes interacting with topographically dynamic landscapes. High diversity in most tropical mountains is tightly linked to bedrock geology, notably areas comprising mafic and ultramafic lithologiesrock types rich in magnesium and poor in phosphate that present special requirements for plant physiology. Mountain biodiversity bears the signature of deep-time evolutionary and ecological processes, a history worth preserving in the face of contemporary environmental changes. 
One Sentence Summary: Evolutionary and ecological processes, acting in geological and climatic contexts over millions of years, have shaped global patterns of mountain biodiversity. 
Mountains are topographically complex regions formed by the interplay of tectonic and volcanic processes. They are intrinsically unstable systems, undergoing significant changes in response to tectonic, erosional, and climatic processes over geologically short time scales. The interaction of mountain substrates, lifeforms, and climate systems - at a range of spatial scales - establishes diverse and unique montane environments (1-4). These environments are transient, and their ongoing changes drive the splitting and subsequent isolation of species ranges, evolutionary adaptation to novel conditions, and consequently population differentiation. These biological processes create a shifting balance between speciation and extinction, in which mountains may act as cradles (areas of especially rapid species origination), museums (areas of especially long-term persistence of species), and graves (areas with especially high rates of extinction) for biodiversity $(1,5)$. The high levels of richness and endemicity of species on most mountains thus reflects enhanced speciation, co-existence, and persistence of evolutionary lineages with distinct evolutionary trajectories.

Mountain regions, especially in the tropics, are home to aggregations of small-ranged species (6) that form highly diverse centers of endemism. These aggregations cannot be predicted from underlying global patterns of species richness (7), or by models based purely on contemporary ecological conditions (3). One possible explanation is that statistical models have not adequately captured the high spatial heterogeneity of ecological and environmental variables characteristic of mountains (3). However, current mountain diversity may also bear the signatures of deep-time evolutionary and ecological processes, driven by changing climate over topographically complex landscapes and by biotic interchange with neighboring areas $(1,5,8)$. The fluctuating dynamics of mountain speciation, evolutionary adaptation, dispersal, persistence, and extinction may ultimately explain diversity patterns across entire continents.

Geological dynamics are increasingly recognized as a key driver of these evolutionary processes, influencing the build-up (and sometimes decline) of mountain diversity $(1,2,4)$. The fossil record allows robust analyses of how species diversification in mountain landscapes has been affected by the break-up and merging of lithospheric plates, in the context of plate tectonic processes $(9,10)$, and by changes in global temperature (11). Linking biogeographical dynamics to detailed reconstructions of mountain formation has become increasingly feasible through such analyses (10). Here, we discuss how evolutionary processes associated with climate history, orogenic processes, and the geological composition of mountain regions shape large-scale geographical patterns of species diversity.

\section{Key roles of mountains for biodiversity}

Over long periods of time, topographic, geological, and geophysical conditions modify the rates and properties of four key processes determining the distribution and diversity of life on Earth: speciation, dispersal, persistence, and extinction (Table 1). The emergence of the Andes, for example, influenced plant diversification and evolution in South America in at least four different ways: (i) by creating a region of novel, high-elevation habitats for species; (ii) as a dispersal barrier to lowland organisms, splitting populations east and west of the mountain range, 
as well as internally in valleys and peaks; (iii) as a north-south corridor for species dispersal; and (iv) as a modifier of environmental, hydrological, and mineralogical conditions in the rest of the continent, through montane effects on the climate system and as a source of mineral components $(12,13)$, released by continued erosion and weathering.

The impact of mountain regions on biodiversity extends far beyond their topographical limits, often affecting entire continental biotas. For example, while the Andes region is, in itself, the most biodiverse region on Earth, Andean orogeny is also considered a key driver for the build-up of biodiversity across all of South America (13). Over roughly the past 10 million years, Andean orogeny has changed the regional topography repeatedly, forcing the Amazon drainage basin to change its course. These changes altered gene flow across the Amazonian lowlands, affecting both terrestrial and aquatic biogeography (14). Mountain regions may also play a role as sources of new evolutionary lineages that later colonize lowland regions. Phylogenetic and biogeographical reconstructions reveal an Andean origin for many Amazonian species, including plants (12), amphibians (15), and tanagers (16).

The influence of specific mountain ranges on the biodiversity of broader regions and entire continents depends on their geographical location, spatial orientation, local biotic context, and history (2). Thus, the European Alps, oriented east-west, have been recognized as refugia for cold-adapted species, but providing insufficient habitat connectivity to enable the persistence of many late-Neogene lineages in Northwestern Europe through the Pleistocene (17). In contrast, 20 the north-south oriented Rocky Mountains have facilitated latitudinal range adjustments, providing dispersal corridors during fluctuating climates and boosting the persistence of North American Neogene populations and species through Pleistocene glacial-interglacial climate cycles (18). These processes are often cited to explain why the tree flora of Western Europe is so depauperate in comparison with the tree flora of North America (18).

The influence of mountains likely differs among taxonomic groups. Speciation in plants, for instance, often reflects adaptations to particular soil geochemistry and mineralogy (19). In birds, speciation may be more susceptible to the breakup of species ranges that follow narrow elevational habitat bands. These include shifts in the tree line and the cloud forest belt (20), and the fragmentation of geographic ranges by major rivers (21). For invertebrates, many speciation events are likely to follow plant specialization linked to the production of specific metabolites.

\section{Evolutionary processes in mountains}

Mountains are hotbeds of speciation, influenced by geological and climatic dynamics over deep time. Mountains can form during both compression and stretching of the lithosphere. Orogenymountain building - typically includes tectonic stacking of lithosphere domains of diverse age, origin, and composition, including upducted ocean floor, emplacement of intrusive magmatic bodies, and building of surface volcanic structures. Mountains are thus lithologically and topographically heterogeneous regions. Evolutionary radiations of species are often associated with phases of active uplift, suggesting that orogenic processes play a role in driving diversification $(14,22,23)$ (Fig. 1A), principally through the recurrent formation, connectivity, 
and disappearance of habitats within mountain ranges (24) (Fig. 1A). Orogenic dynamics, including, surface uplift and formation of intermontane basins and subsequent erosion, create shifts in hydrological catchments, river flows, and nutrient fluxes. These processes change soil composition and nutrient levels, driving adaptation of plants and their associated biota in new habitat types. Mountain formation also affects local climate, creating zones of rain shadow or persistent mist, with a strong filtering effect on species communities (2).

During the past $\sim 2.6$ million years, the climatic cyclicity of the Quaternary has impelled dynamic shifts in habitat connectivity that stimulated speciation in certain groups (25) (Fig. 1B). These changes are linked to the Milankovitch eccentricity cycle with a periodicity around 100 thousand years, possibly amplified by the c. 41,000-year obliquity cycle, and further thought to instigate cyclic, climate-driven habitat changes that drive temporally rapid "species pumps" (10, 25, 26). Vegetation belts moved upslope during warm and wet interglacials, leading to the fragmentation of populations and genetic divergence. As temperatures dropped again in glacial episodes, vegetation belts moved downslope, forcing secondary contact of populations, leading to founder effects, disruptive selection, and character displacement, thus creating the conditions classically associated with allopatric speciation. In a process-based simulation model of range dynamics in South America, Rangel et al. (5) recently found support for these predictions, with the Andes acting as an episodic species pump (Fig. 1B).

At large spatial and temporal scales, these processes can yield very different distributions of species, some that descended from ancient, isolated lineages, and some that originated from recent radiations. The relative contribution of these two groups to mountain diversity varies greatly among mountain regions (compare Fig. 2 inhere with Fig. 3 in Rahbek et al. (3)). Badgley et al. (4) defined specific, testable predictions from three (non-exclusive) models for the occurrence of radiations in topographically complex landscapes: i) active tectonic dynamics drive speciation; ii) speciation is constantly elevated in the habitat mosaic of topographically complex areas, and iii) climate-driven immigration stimulates speciation. In an empirical study of North American rodents, Badgley and colleagues found some support for the first and third scenario (4). In a recent global analysis, Antonelli et al. (2) also found a significant effect of mountain relief on species diversity, although with relatively weak effects of erosion and erosive potential, which are otherwise formative influences within geologically dynamic landscapes.

\section{Mountains - cradles, museums, or graves of diversity?}

Stebbins (27) famously asked whether species diversity in the tropics is so high because the tropics are "cradles" (i.e., areas of especially rapid species origination) or "museums" (i.e., areas of especially long-term persistence of species). Other metaphors have since been added (Table 1), including the notion of "graves" to describe geographical areas with especially high rates of extinction. Identification of graves from contemporary distribution data or fossils remains elusive. However, their existence, and location, and timing have been predicted by process-based

40 simulation models (28) of geographical range-dynamics through time, driven by simulated paleoclimates (5). 
For the most diverse tropical mountains, it appears that the answer to Stebbins' question is that mountains are both cradles and museums (Fig. 2C) (29). To exemplify, the Andes are not only home to several recently diversified species clusters with high phylogenetic relatedness, but also host many old, relictual lineages aggregated in centers of endemism (30). The combination of both cradle and museum effects appears crucial to the emergence of the Andes as the most diverse region on Earth (3).

Whereas the Andes have high numbers of both early-divergent and recently-derived species, the mountain regions of Southeast Asia are primarily occupied by species that are recently derived (Fig. 2). A plausible explanation for these regionally-distinct patterns is that tropical mountain ranges with very high peaks and more rugged terrain, such as the Andes and Southeast Asia, are home to a high-elevation biota characterized by a small number of lineages adapted to colder environments. These few lineages may become regionally very species-rich as a product of rapid, local diversification (31). In the Andes, this process may have occurred more repeatedly than in Southeast Asia. In contrast, the Afromontane regions and the Atlantic Rainforest mountain region of South America both show a greater predominance of earlydivergent species.

In a simulation of temporal range dynamics of the South American biota, cradles derived from Andean founders (in each simulation, one initial "seed" species) were found to be concentrated along the Andean slopes, whereas graves tended to be at lower elevations in the upper Amazon Basin (5). Biotas derived from Atlantic Forest founders, in contrast, had a much higher spatial coincidence of cradles and graves. These results align with the view that topographic complexity and elevational climate gradients promote range fragmentation and act as cradles, while at the same time acting as museums by providing climatic refugia from extinction $(5,26,32)$. The simulations also revealed that the spatial positions of cradles, museums, and graves can be dynamic, changing shape, size, and intensity over time and in response to Quaternary climate cycles (5). These temporal and spatial dynamics imply that inferring cradles or museums based on the current distributions of extant young and old lineages may be misleading.

\section{Geological heterogeneity and biodiversity}

The potential importance of mountain geology, including the mineralogical composition of substrates, has been highlighted in recent work $(1,2,4)$. Mountain substrates generally differ substantially from those of surrounding lowland basins, which are frequently dominated by eroded materials derived from the mountains and deposited in valleys and plains. Mineral composition and nutrient levels in the soil affect plant physiology, vegetation composition, primary productivity, and consequnetly species diversity. In addition, mountain regions with a high level of geological heterogeneity are likely to support higher levels of species spatial turnover and local endemic forms, particularly among plants. However, empirical studies establishing a relationship between diversity of edaphic conditions and plant species diversity are 
scarce, and little is known about how edaphic heterogeneity affects diversity at higher trophic levels.

In a recent global analysis, which also confirmed the classic correlation of species diversity with topographic relief and climate $(3,33,34)$, Antonelli and co-workers (2) found correlations of species richness of mammals, birds, and amphibians with both long-term and short-term erosion rates and a measure of soil diversity. Although the association was generally weaker than the correlation of richness with climatic variables, soil heterogeneity was consistently a significant predictor of richness across multiple biogeographical regions of the world. They suggested that soil heterogeneity underlies fine-scale habitat turnover, creating novel habitats and ecological opportunities, thereby increasing local and regional species richness. In Fig. 3, we further explore the relationship between species diversity and bedrock heterogeneity, as measured by the number of major categories of bedrock that are represented within each mountain region.

Geological heterogeneity, simplified in this way, does not explain much of the variation in total species richness, and fails to account for the high richness of small-ranged species characteristic of mountains at low latitudes (compare Fig. 3A in this paper with Fig. 3 in Rahbek et al. (3)). This disconnect may imply that the way rock classes translate into ecologically relevant soil properties is significantly more complex than captured by our simple classification. An ecologically relevant special case is presented by the presence or absence of mafic and ultramafic rocks (Fig. 3C). Soils originating from ultramafic rocks have a well-described effect on plant adaptations and diversity. Their unusual geochemistry, with high magnesium content and low availability of phosphorus (35), demands specific adaptations and slows growth rates for plants. The vegetation of serpentine soils, which form on ultramafic bedrock, is highly specialized, generally woody, with high levels of phenols and lignin in leaves, driving secondary effects on the cycling of nutrients in the decomposition of leaf litter. Serpentine soils pose strong selective filters for plants, excluding many groups but fostering radiations of clades that tolerate these soils (36). Ultimately, habitat heterogeneity, patchiness, and specialized dietary adaptations of herbivores may impel speciation cascades in these habitats across all major groups of organisms, including vertebrates.

Mapping the global occurrence of larger, contiguous mafic and ultramafic rock domains in mountain regions (Fig 3B) reveals that all hyper-diverse mountain regions are rich in such rocks. Intercalated mafic and ultramafic rock domains often form part of ophiolites, slivers of oceanic lithosphere upducted and emplaced within continental orogens during plate collision. Emplacement of ophiolites is thus an integral part of the orogenic processes forming cordilleran mountain chains. Ultramafic and mafic rock, mostly associated with ophiolites, underlie $>5 \%$ of the crimson area in Fig 3B.

Almost all the most biologically diverse mountain regions have three features in common: high rock diversity, presence of upducted oceanic lithosphere, and a geographical location in the humid tropics (Fig. 3C). In contrast, mountains with low rock diversity and without ultramafic components, even in the mesic tropics, tend to be relatively species-poor. Mountain regions 
without oceanic lithosphere components show little relationship between biodiversity and rock diversity, regardless of climatic zone. Understanding the geochemical contrast between continental and oceanic lithosphere components may thus be key to understand how bedrock geology might influence the production and maintenance of species richness.

The high turnover of distinct habitat patches created on geologically heterogeneous surfaces, even within the same local climate, might contribute significantly to the process of population-splitting and differentiation that characterizes mountain speciation dynamics. Plant characteristics on soils derived from emplaced ultramafic rocks may also pose challenges for herbivorous animals. Soil geochemistry affects plant metabolism and may increase the production of secondary metabolites, with plants on these soils investing heavily in chemical and physical defenses against herbivores. Such adaptive challenges facing the plant-dependent fauna may stimulate a higher rate of adaptive divergence among consumers during phases of population isolation, and thus precipitate locally extremely high rates of diversification, as seen in nectarivores (e.g. hummingbirds) and frugivores (e.g. New World sparrows and tanagers).

\section{Concluding perspective}

The idea that geology and biology are intertwined runs as a consistent undertone in von Humboldt's Cosmos (37), expressed as his "unity of nature." Later, in 1880, Wallace (38) inferred the recurrence of glaciations in Earth's history from the distribution of related animal species on islands in the Indo-Pacific. While much research has been stimulated by these early works, the lack of data and robust analytical frameworks has long hampered efforts to fully incorporate biological and geological processes into rigorous statistical models for mountain species diversity and evolution (2).

New methods in geomorphology, including stable isotope altimetry, thermochronology,

and advances in digital multispectral imaging (39), are paving the way for accurate reconstructions of geological dynamics, thus creating a strong foundation for testing evolutionary theories on the origin and maintenance of mountain diversity over time. Combined with genomic sequencing, these approaches may allow inference of the timing, and perhaps even the location (using environmental ancient DNA), of changes in effective population sizes and genetic bottlenecks. The next generation of geologically and evolutionarily explicit models may, in this way, radically change our understanding of biotic evolution and resolve the historically contentious debate over the extent to which ecological and evolutionary processes, historical contingency, or simply stochasticity and time shape the diversity and distribution of life on Earth.

35 The idea that heterogeneity in geological substrate properties may directly impact evolution is still based primarily on circumstantial evidence, supported by statistical patterns with weak or mixed correlations with diversity (as in Fig. 3) (1, 2, 4). Quantifying the specific geological variables that are biologically relevant and distinguishing topographic from geochemical effects remain open challenges for establishing causality. Alternative, processbased explanations should be sought in the interactions between individual mountain regions and 
other components of the Earth System, especially the atmosphere and the oceans. An emerging conjecture is that mountains are hubs of innovation to such a degree that Earth's biodiversity would have been completely different in the absence of high mountain regions. For example, do mountains in the tropics provide exceptional environmental conditions that encourage fixation of novel mutations and drive localized adaptive change in plants, in turn driving speciation cascades (i.e., the speciation of a group leading to speciation in other groups)? Flenley (40) suggested that the higher ultraviolet B levels on tropical mountain peaks might directly impact DNA, causing a high rate of mutation and leading to evolutionary innovation. According to this hypothesis, climatic warm periods that drive species upslope, such as interglacials, should be followed by increased levels of speciation.

A growing consensus holds that models explicitly incorporating geological and ecological dynamics must take as their starting point the holistic view that all of these processes, acting at different temporal and spatial scales, shape contemporary patterns of biodiversity. The looming challenge is to incorporate these insights within a unified model that generates predictions that can be tested with independent data.

\section{References and Notes:}

1. J. Fjeldså, R. C. K. Bowie, C. Rahbek, The role of mountain ranges in the diversification of birds. Annu. Rev. Ecol. Evol. Syst. 43, 249-265 (2012).

2. A. Antonelli et al., Geological and climatic influences on mountain biodiversity. Nature Geoscience 11, 718 (2018).

3. C. Rahbek, M. K. et al., Humboldt's enigma: what causes global patterns of mountain biodiversity? Submitted review ms to Science (2019).

4. C. Badgley et al., Biodiversity and topographic complexity: Modern and geohistorical perspectives. Trends Ecol. Evol. 32, 211-226 (2017).

5. T. F. Rangel et al., Modeling the ecology and evolution of biodiversity: Biogeographical cradles, museums, and graves. Science. 361, eaar5452 (2018).

6. C. Rahbek et al., Predicting continental-scale patterns of bird species richness with spatially explicit models. Proc. Roy. Soc. B. 274, 165-174 (2007).

7. W. Jetz, C. Rahbek, R. K. Colwell, The coincidence of rarity and richness and the potential signature of history in centres of endemism. Ecol. Lett. 7, 1180-1191 (2004).

8. A. Antonelli et al., Conceptual and empirical advances in Neotropical biodiversity research. PeerJ. 6, e5644 (2018).

9. A. Zaffos, S. Finnegan, S. E. Peters, Plate tectonic regulation of global marine animal diversity. Proc. Natl. Acad. Sci. USA 114, 5653-5658 (2017).

10. C. Hoorn, A. Perrigo, A. Antonelli, Eds., Mountains, Climate and Biodiversity (Wiley-Blackwell, London, UK, 2018).

11. C. H. Oliveros et al., Earth history and the passerine superradiation. Proc. Natl. Acad. Sci. USA 116, 7916-7925 (2019).

12. A. Antonelli, J. A. Nylander, C. Persson, I. Sanmartín, Tracing the impact of the Andean uplift on Neotropical plant evolution. Proc. Natl. Acad. Sci. USA 106, 9749-9754 (2009). 
13. F. Luebert, M. Weigend, Phylogenetic insights into Andean plant diversification. Front. Ecol. Evol. 2 (2014).

14. C. Hoorn et al., Amazonia through time: Andean uplift, climate change, landscape evolution, and biodiversity. Science 330, 927-931 (2010).

\section{J. C. Santos et al., Amazonian amphibian diversity
Andean lineages. PLoS Biology. 7, e1000056 (2009).}

16. R. E. Sedano, K. J. Burns, Are the Northern Andes a species pump for Neotropical birds? Phylogenetics and biogeography of a clade of Neotropical humms (Aves: Thraupini). J. Biogeogr. 37, 325-343 (2010).

17. K. D. Bennett, P. C. Tzedakis, K. J. Willis, Quaternary refugia of North European trees. J. Biogeogr. 18, 103-115 (1991).

18. Reid, E. M., British floras antecedent to the Great Ice Age. Proc. Roy. Soc. B. 118, 197-241 (1935).

19. P. A. Fine, D. C. Daly, G. V. Muñoz, I. Mesones, K. M. Cameron, The contribution of edaphic heterogeneity to the evolution and diversity of Burseraceae trees in the Western Amazon. Evolution. 59, 1464-1478. (2005).

20. G. R. Graves, Elevational correlates of speciation and intraspecific geographic-variation in plumage in Andean forest birds. Auk 102, 556-579 (1985).

21. L. N. Naka, R. T. Brumfield, The dual role of Amazonian rivers in the generation and maintenance of avian diversity. Science Advances. 4, eaar8575 (2018).

22. J. T. Eronen, C. M. Janis, C. P. Chamberlain, A. Mulch, Mountain uplift explains differences in Palaeogene patterns of mammalian evolution and extinction between North America and Europe. Proc. Roy. Soc. B. 282, 20150136 (2015).

23. A. Favre et al., The role of the uplift of the Qinghai-Tibetan Plateau for the evolution of Tibetan biotas. Biol. Rev. 90, 236-253 (2015).

24. D. Craw, P. Upton, C. P. Burridge, G. P. Wallis, J. M. Waters, Rapid biological speciation driven by tectonic evolution in New Zealand. Nature Geoscience 9, 140-144 (2016).

25. B. Nevado, N. Contreras-Ortiz, C. Hughes, D. A. Filatov, Pleistocene glacial cycles drive isolation, gene flow and speciation in the high-elevation Andes. New Phytol 219, 779-793 (2018).

26. J. Fjeldså, Geographical patterns for relict and young species of birds in Africa and South America and implications for conservation priorities. Biodivers. Conserv. 3, 207-226 (1994).

27. Stebbins, G. L., Flowering plants: Evolution above the species level (Harvard University Press, MA, 1974).

28. S. R. Connolly, S. A. Keith, R. K. Colwell, C. Rahbek, Process, mechanism, and modeling in macroecology. Trends Ecol. Evol. 32, 835-844 (2017).

29. C. R. Hutter, S. M. Lambert, J. J. Wiens, Rapid diversification and time explain amphibian richness at different scales in the tropical Andes, Earth's most biodiverse hotspot. Am. Nat. 190, 828-843 (2017).

30. N. A. Hazzi, J. S. Moreno, C. Ortiz-Movliav, R. D. Palacio, Biogeographic regions and events of isolation and diversification of the endemic biota of the tropical Andes. Proc. Natl. Acad. Sci. USA 115, 7985-7990 (2018).

31. S. Madriñán, A. J. Cortés, J. E. Richardson, Páramo is the world's fastest evolving and coolest biodiversity hotspot. Front. Genet. 4 (2013)

$45 \quad$ New Phytol. 212, 510-522 (2016).

33. C. Rahbek, G. R. Graves, Multiscale assessment of patterns of avian species richness. Proc. Natl. Acad. Sci. USA 98, 4534-4539 (2001). 
34. W. Jetz, C. Rahbek, Geographic range size and determinants of avian species richness. Science 297, 1548-1551 (2002).

35. Batjes, N. H., "Global distribution of soil phosphorous retention potential" (ISRIC Report, World Soil Information, Wageningen, 2011).

36. B. L. Anacker, J. B. Whittall, E. E. Goldberg, S. P. Harrison, Origins and consequences of serpentine endemism in the California flora. Evolution 65, 365-376 (2011).

37. A. von Humboldt, Cosmos: A sketch of a physical description of the universe (Harper \& Brothers, New York, 1858).

38. A. R. Wallace, Island life. Or, the phenomena and causes of insular faunas and floras, including a revision and attempted solution of the problem of geological climates (MacMillan and Co., London, 1880).

39. H. Viles, Technology and geomorphology: Are improvements in data collection techniques transforming geomorphic science? Geomorphology 270, 121-133 (2016).

40. J. R. Flenley, Why is pollen yellow? And why are there so many species in the tropical rain forest? J. Biogeogr. 38, 809-816 (2011).

41. B. G. Holt, J.-P. Lessard, M. K. Borregaard, S. A. Fritz, M. B. Araújo, D. Dimitrov, P.-H. Fabre, C. H. Graham, C. R. Graves, K. A. Jønsson, D. Nogués-Bravo, Z. Wang, R. J. Whittaker, J. Fjeldså, C. Rahbek, An update of Wallace's zoogeographic regions of the world. Science 339, 74-78 (2013).

\section{ACKNOWLEDGMENTS}

Funding: C.R, M.K.B, R.K.C., B.H., D.N.B, K.R, R.J.W, and J.F wish to thank the Danish National Research Foundation for its support of the Center for Macroecology, Evolution and Climate, CMEC, (DNRF96). C.R. was funded by a Villum Investigator grant (no. 25925) from The Villum Foundation; M.K.B. was supported by an Individual Fellowship from Marie Sklodowska-Curie actions (IDEA707968); A.A. was supported by the Swedish Foundation for Strategic Research, the Swedish Research Council and the Knut and Alice Wallenberg Foundatio; C.M.Ø.R. received funding from the VILLUM Foundation's Young Investigator Programme (VKR023452); M.T.R. was support by Novo Nordisk Foundation (NNF16SH0020278). Author contributions: C.R. and J.F. designed the CMEC mountain research program. C.R. and M.B.K. coordinated the work, performed all analyses and led the writing with contributions from all coauthors. The authors declare no conflicts of interest. 


\begin{tabular}{|c|c|c|c|}
\hline $\begin{array}{c}\text { Role of } \\
\text { Mountains }\end{array}$ & Process & Mechanism & Exemplar Questions \\
\hline Cradles & $\begin{array}{l}\text { Speciation } \\
\text { and } \\
\text { diversification }\end{array}$ & $\begin{array}{l}\text { Fragmentation of species } \\
\text { ranges, with potential for } \\
\text { local adaptation of } \\
\text { populations. }\end{array}$ & $\begin{array}{l}\text { What drives adaptive } \\
\text { diversification in } \\
\text { mountains, and how } \\
\text { important is non-adaptive } \\
\text { speciation? }\end{array}$ \\
\hline $\begin{array}{l}\text { Innovation } \\
\text { Hubs }\end{array}$ & $\begin{array}{l}\text { Adaptive } \\
\text { radiation }\end{array}$ & $\begin{array}{l}\text { Adaptive response of } \\
\text { isolated populations in a } \\
\text { heterogeneous } \\
\text { environment to local } \\
\text { selection. }\end{array}$ & $\begin{array}{l}\text { Do higher environmental } \\
\text { UV levels directly affect } \\
\text { mutation rates? Do } \\
\text { localized, distinctive soils } \\
\text { generate speciation } \\
\text { cascades? }\end{array}$ \\
\hline Elevators & $\begin{array}{l}\text { Dispersal } \\
\text { (passive) }\end{array}$ & $\begin{array}{l}\text { Passive movement of } \\
\text { species and their } \\
\text { substrates from lowlands } \\
\text { caused by surface uplift. }\end{array}$ & $\begin{array}{l}\text { How can we differentiate } \\
\text { between passively } \\
\text { uplifted species and } \\
\text { actively dispersed ones? }\end{array}$ \\
\hline Corridors & $\begin{array}{l}\text { Dispersal } \\
\text { (enhanced) }\end{array}$ & $\begin{array}{l}\text { Continuous linkage of } \\
\text { similar highland habitats. }\end{array}$ & $\begin{array}{l}\text { What are the relative } \\
\text { contributions of local } \\
\text { recruitment vs. long- } \\
\text { distance dispersal to high- } \\
\text { elevation biotas? }\end{array}$ \\
\hline Barriers & $\begin{array}{l}\text { Dispersal } \\
\text { (blocked) }\end{array}$ & $\begin{array}{l}\text { Vicariance of lowland } \\
\text { species, preventing } \\
\text { further gene exchange. }\end{array}$ & $\begin{array}{l}\text { How can we test this } \\
\text { hypothesis, given } \\
\text { uncertainties in } \\
\text { paleoclimatic models, } \\
\text { molecular data, and } \\
\text { geological } \\
\text { reconstructions? }\end{array}$ \\
\hline Reservoirs & Maintenance & $\begin{array}{l}\text { Persistence of species } \\
\text { during climate change by } \\
\text { tracking their climate } \\
\text { niche through elevational }\end{array}$ & $\begin{array}{l}\text { How do species persist on } \\
\text { mountains with limited } \\
\text { possibility for elevational } \\
\text { migration or discordant }\end{array}$ \\
\hline
\end{tabular}




\begin{tabular}{|c|c|c|c|}
\hline & & range shifts. & $\begin{array}{l}\text { shifts in temperature and } \\
\text { precipitation? }\end{array}$ \\
\hline Refugia & Maintenance & $\begin{array}{l}\text { Mountains acting as } \\
\text { sources to restock } \\
\text { lowlands after episodes of } \\
\text { climate-driven extinction. }\end{array}$ & $\begin{array}{l}\text { How representative is the } \\
\text { Last Glacial Maximum } \\
\text { for the role of mountains } \\
\text { as refugia in the context } \\
\text { of previous glaciations? }\end{array}$ \\
\hline Museums & Maintenance & $\begin{array}{l}\text { Collapse of once-larger } \\
\text { ranges, leaving remnant } \\
\text { populations in favorable } \\
\text { mountain microclimates. }\end{array}$ & $\begin{array}{l}\text { How important is climatic } \\
\text { and topographic } \\
\text { complexity for the } \\
\text { persistence of lineages? }\end{array}$ \\
\hline Sinks & Extinction & $\begin{array}{l}\text { Local extirpation due to } \\
\text { patchy habitat availability. }\end{array}$ & $\begin{array}{l}\text { How does the role of } \\
\text { sinks vary with latitude? }\end{array}$ \\
\hline Graves & Extinction & $\begin{array}{l}\text { Upslope shifts of } \\
\text { mountain species during } \\
\text { warm interglacials until } \\
\text { species exceed their } \\
\text { thermal tolerance. }\end{array}$ & $\begin{array}{l}\text { How important will } \\
\text { mountaintop extinctions } \\
\text { be, compared to human- } \\
\text { induced landscape } \\
\text { changes? }\end{array}$ \\
\hline
\end{tabular}

Table 1. Proposed biogeographical roles of mountains, the key processes involved, their underlying mechanisms, and examples of outstanding research questions. 


\section{A. Orogeny - creating new species over millions of years}
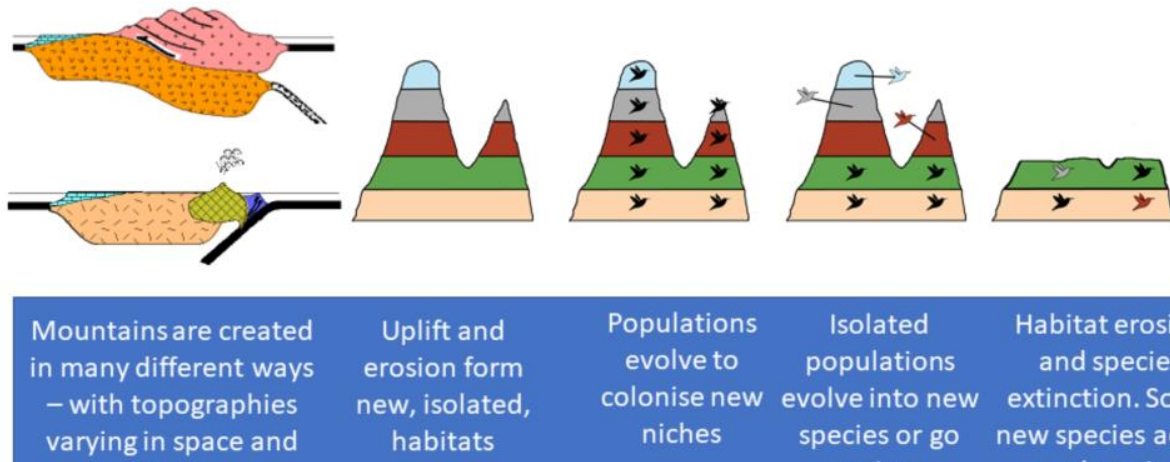

time

\section{Uplift and \\ erosion form \\ new, isolated, \\ habitats}

\section{Populations \\ evolve to \\ Isolated \\ populations \\ colonise new evolve into new \\ niches \\ species or go \\ extinct}

Habitat erosion

and species

extinction. Some

and survive

Deep geological time

b) Flickering connectivity - speciation driven by mountain climate cycling
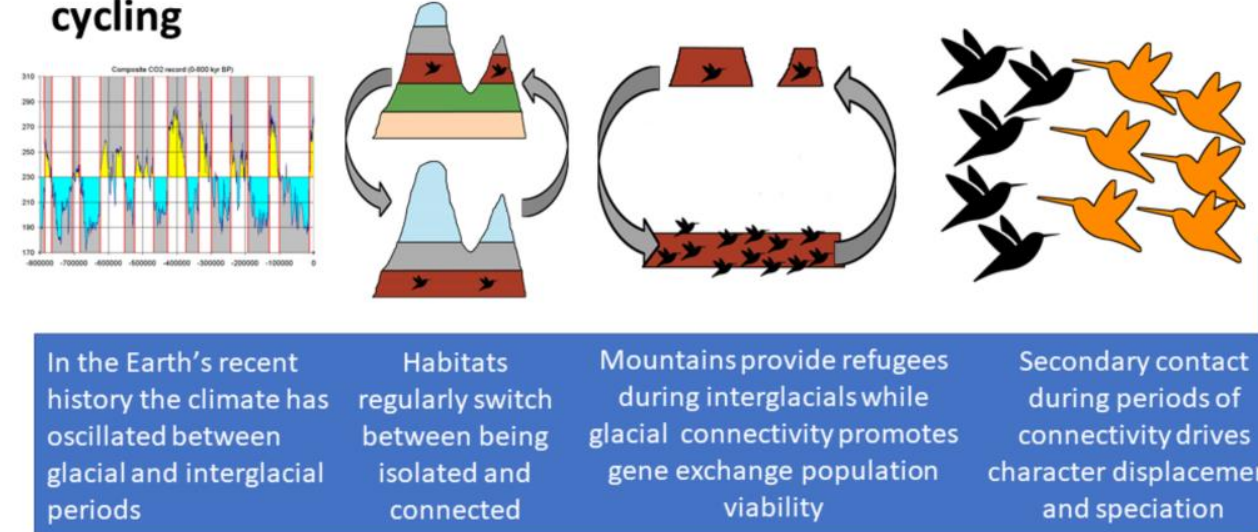

Secondary contact

during periods of

connectivity drives

character displacement

and speciation

Two million

Present day

years ago

Figure 1. Schematic view of two temporal scales of buildup of mountain diversity. A) Mountain ranges are tectonically dynamic over millions of years, leading to isolated novel environments and the long-term adaptation of species colonizing these new habitats. B) Climatic dynamics in the Quaternary induced by Milankovitch orbital cycles cause habitats and climatic zones to move up and down mountain slopes, repeatedly, on the scale of tens to hundreds of thousands of years. These movements lead to rapid, repeated dynamics of range splitting and secondary contact, stimulating diversification. 


\section{A. Early divergent species}

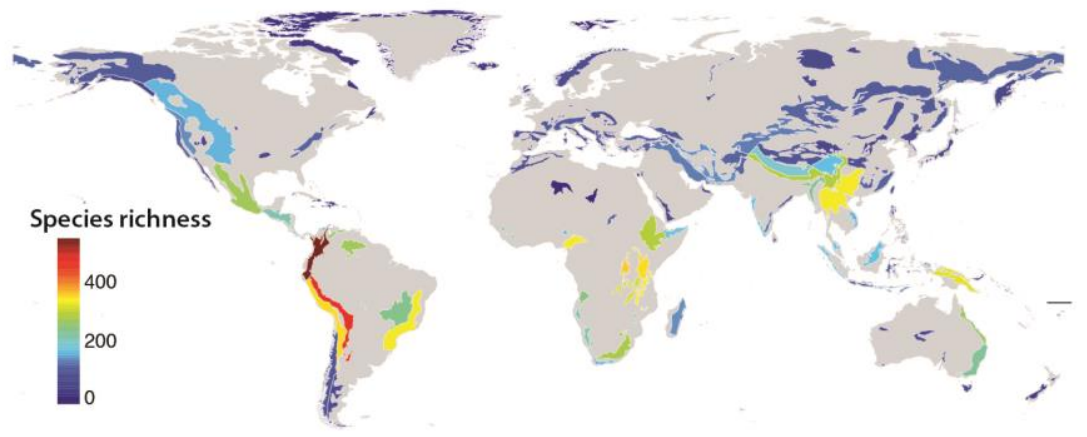

\section{B. Recently derived species}

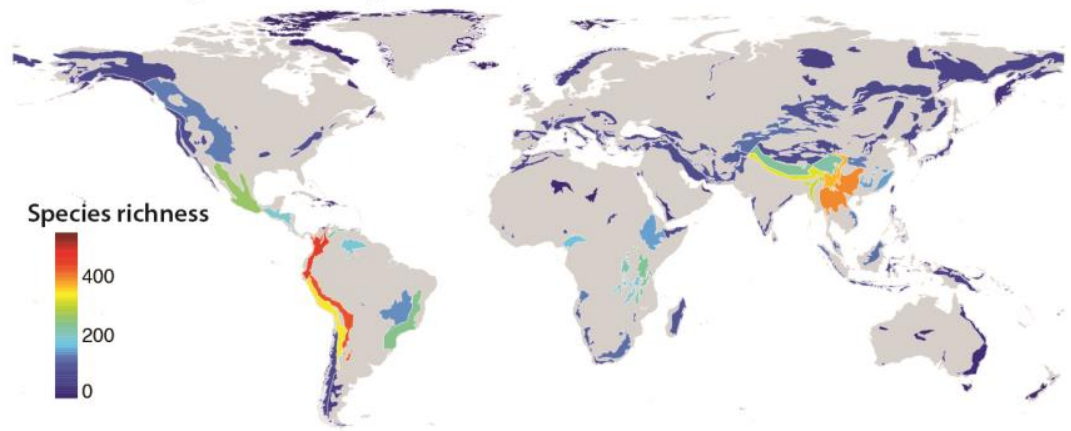

\section{Overlap}

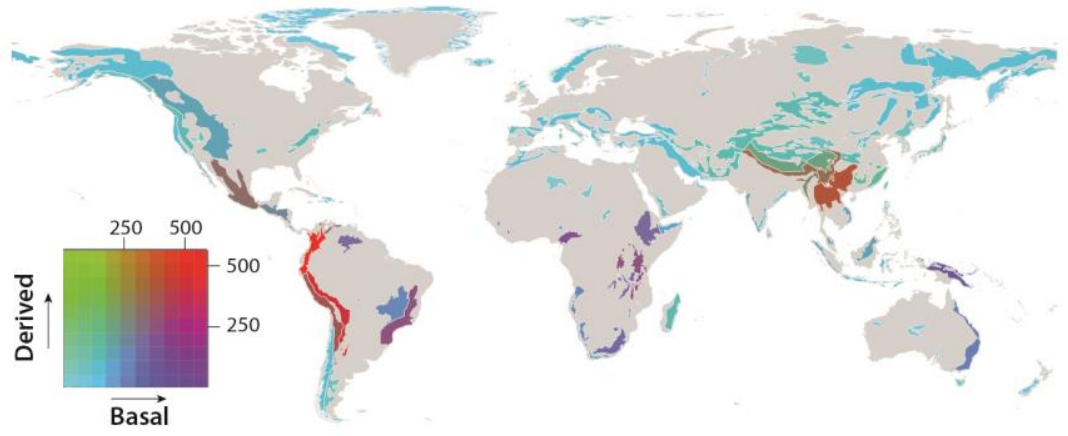

Figure 2. Global pattern of early-divergent and recently-derived species richness in mountain regions. A. The number of early-divergent birds, mammals and amphibians, defined as the $25 \%$ of species that are separated from the crown node of their class in the molecular phylogeny by the smallest, ranked node distance. B. The number of species among the $25 \%$ with the largest, ranked root distance. C. The overlap of early-divergent and recently-derived species reveals which mountain regions represent museums (purple), cradles (green) or both (red). Cyan areas have low richness of both groups. Distribution and phylogeny data are from Holt et al. (41) and Mountain Regions are as defined in Rahbek et al. (3). The classification into early-divergent or recently derived was done independently for each class, and values for all three classes were added to give the depicted total. 

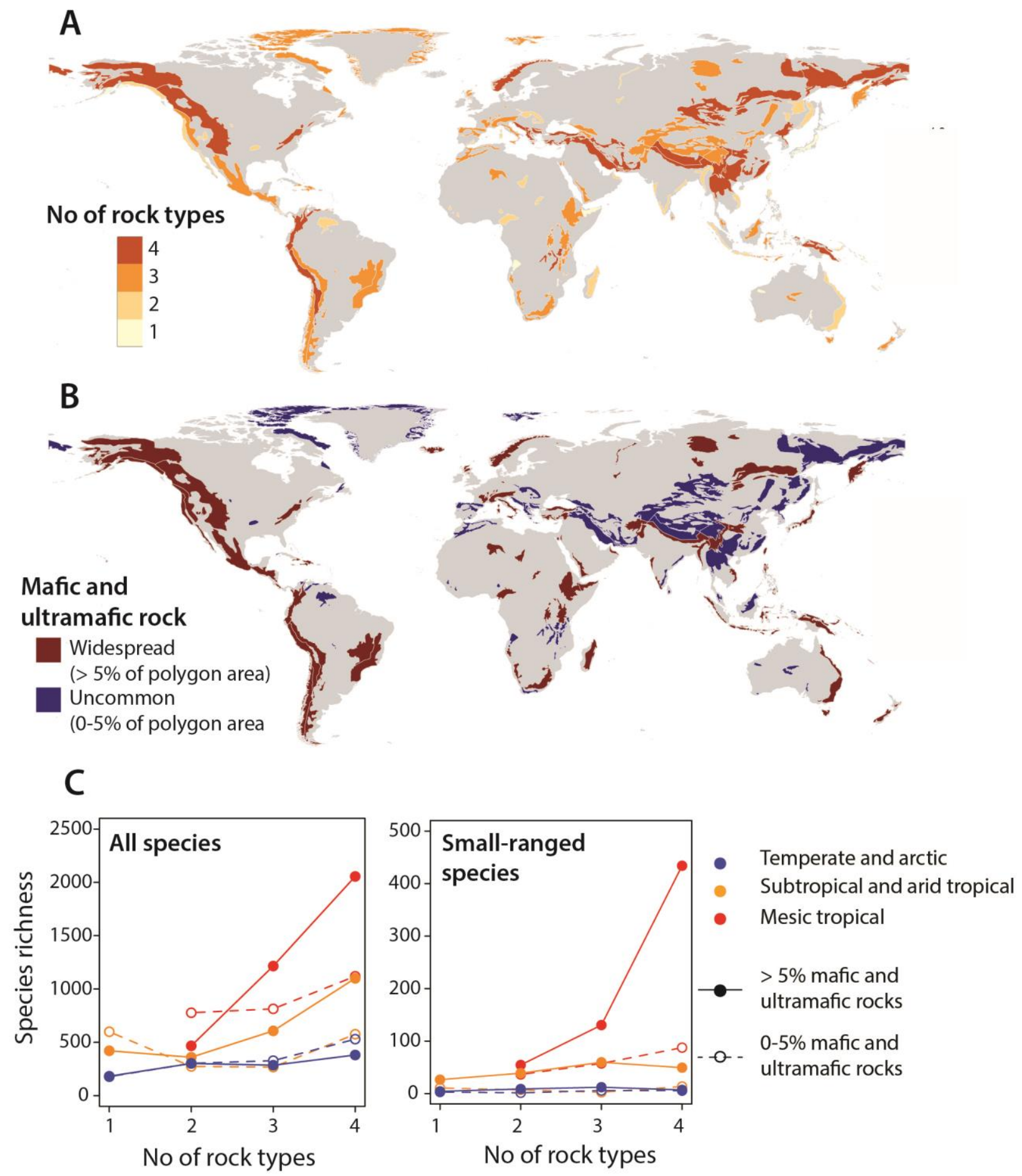
Figure 3. Mountain geology and vertebrate diversity. A. Geological diversity, quantified by categorizing rocks based on mineral composition and depositional setting, and counting the number of categories occupying at least $5 \%$ of the area of each mountain region. Categories are 1) siliciclastic and 2) carbonate sedimentary rocks, 3) metamorphic rocks, and 4) felsic and 5) mafic igneous rocks. Note that the map shows counts, not categories. B. The occurrence of mafic and ultramafic rocks, most commonly derived from upducted oceanic lithosphere in mountain regions. Soils formed on these rocks have distinct geochemical properties that require specialized plant metabolism. C. Total species richness and small-ranged species richness of mountain regions, as a function of geological diversity, climate band, and the widespread occurrence of 10 mafic and ultramafic rocks. Points show the mean value for each category. The richest mountain regions of the world are geologically diverse mountains in the tropics with ultramafic rocks. Mountain regions follow Rahbek et al. (3), and the geological data are compiled from sources on the onegeology.com website. 